\title{
A InstitucionalizaÇão das Práticas DE RESPONSABILIDADE SOCIAL: UM ESTUDO DA COMPANHIA DE ÁGUA E ESGOTO DO CEARÀ
}

\section{RESUMO}

O tema Responsabilidade Social Empresarial (RSE) tem permeado o campo dos estudos organizacionais. Ao mesmo tempo, as empresas têm aprimorado ações de RSE que ganham forma, conforme o contexto. Na medida em que estas práticas são sistematizadas, as organizações passam por mudanças. Em muitos casos, porém, a sistematização não ocorre, inviabilizando o alinhamento da RSE à estratégia corporativa. Diante disso, este estudo visa investigar o processo de institucionalização da RSE, na Companhia de Água e Esgoto do Ceará, à luz do modelo de Tolbert e Zucker (1999). Nesta concepção, a institucionalização ocorre mediante as fases de habitualização, objetivação e sedimentação. Trata-se de uma pesquisa quantitativa, exploratória e descritiva, realizada mediante um survey. O questionário foi estruturado a partir dos temas valores, transparência e governança; público interno; e meio ambiente, dos indicadores Ethos. O tratamento dos dados foi realizado com o SPSS e o Excel. Quanto aos resultados, em relação à habitualização, a empresa investe em novas tecnologias para melhorar seus serviços e segue as determinações da agência reguladora. No tocante à objetivação, a empresa realiza estudos sobre RSE e busca alinhar as práticas a seus objetivos. Há consenso quanto à adoção de uma postura transparente e ética e acerca do valor de uma estrutura própria para a RSE. Quanto à sedimentação, a disseminação da RSE traz legitimidade às ações, havendo um alto índice de concordância quanto ao comprometimento da empresa com o desenvolvimento da sociedade. Os resultados evidenciam que, embora haja progressos moderados, a institucionalização ainda está em andamento.

Palavras-chave: Institucionalização; Responsabilidade social empresarial; Companhia de Água e Esgoto

\section{ABSTRACT}

The theme of Corporate Social Responsibility (CSR) has permeated the field of organizational studies. Likewise, organizations have improved CSR
Teresa Cristina Aguiar

Lima

Mestrado em Administração pela

UFC

Especializaçãoem Administração de

Recursos Humanos pela UFC

teresa_lima00@yahoo.com.br

Augusto Cézar de Aquino

Cabral

Doutorado em Administração pela

UFMG

Mestre em Administração pela

UECE

cabral@ufc.br

\section{Maria Naiula Monteiro \\ Pessoa \\ Doutora em Engenharia de \\ Produção naiula@ufc.br}

\section{Sandra Maria dos Santos Doutora em Economia smsantos@ufc.br}

\section{Debora Cardoso do Nasci- mento \\ Graduanda em Contabilidade pela UFC deboracardoso33@hotmail.com}

Recebido em 11/outubro/2010 Aprovado em 30/junho/2011 
practices, which are shaped according to the context. As such practices become systematized, organizations undergo changes. However, in many cases, the systematization does not occur, hindering the alignment of CSR to the corporate strategy. Given this scenario, this research aims at investigating the process of institutionalization of CSR, at the Water and Sewage Company of Ceará, in light of the Tolbert and Zucker (1999) model. In this model, institutionalization occurs through the phases of habitualization, objectification and sedimentation. The study is of an exploratory, descriptive and quantitative nature and was carried out through a survey. The questionnaire was structured based on the themes values, transparency and governance; internal public; and environment of the Ethos indicators. The data were analyzed with the SPSS and Excel. As for the results, in relation to habitualization, the company invests in new technologies to improve services and follows determinations of the regulatory agency. In regard to objectification, the company conducts studies on CSR and attempts to align practices to its goals. There is consensus regarding the adoption of a transparent and ethical posture and the value of a structure specific to the CSR. In relation to sedimentation, the dissemination of CSR legitimates practices, and there is a high level of agreement regarding the commitment of the company to the development of society. Results show that, although there are moderate advances, institutionalization is still taking place.

Key words: Institutionalization, Corporate Social Responsibility, Water and Sewage Company 
Teresa Cristina Aguiar Lima, Augusto Cézar de Aquino Cabral, Maria Naiula Monteiro Pessoa, Sandra Maria dos Santos, Debora Cardoso do Nascimento

\section{INTRODUÇÃO}

O tema Responsabilidade Social Empresarial (RSE) tem permeado o campo dos estudos organizacionais com bastante assiduidade. Ao mesmo tempo, as empresas têm aprimorado técnicas e ferramentas de aplicação de RSE que ganham forma, de acordo com o contexto em que são utilizadas, sob uma perspectiva estratégica. Gonçalves Filho et al. (2009) argumentam que a noção de responsabilidade social não é nova, visto que já na segunda metade do século XIX havia iniciativas nos Estados Unidos e no Reino Unido no sentido de proporcionar melhores condições de trabalho, com o reconhecimento da influência dessa medida na produtividade. No contexto brasileiro, os autores evidenciaram que a prática da responsabilidade social alinha-se à busca de vantagens para a cadeia de valor das empresas. Oliveira et al. (2006), em estudo no setor calçadista exportador do Ceará, salientam que a responsabilidade social visa, em especial, ao marketing social e à produtividade.

No que se refere à conceituação da RSE, não há consenso. Porém, verifica-se uma convergência em torno da crença de que o bem-estar coletivo deve transcender o alcance dos objetivos organizacionais, inclusive os empresarias, como o lucro. A visão de Melo Neto e Froes (1999), por exemplo, centra-se na ideia de contrapartida social, devendo a empresa prestar contas com a sociedade, com a fonte dos recursos humanos e com os materiais utilizados. Em sua trajetória de evolução, o conceito que, em muitos casos, foi tratado como filantropia ou como mero reflexo de imposições legais ou dos benefícios que suas práticas trazem - em termos de imagem, tomando como exemplo -, ocupa hoje posição de destaque. Quer seja motivada por razões instrumentais ou por razões ideológicas, a adesão à RSE tende a ser um diferencial competitivo.

$\mathrm{Na}$ medida em que as práticas de RSE são sistematizadas, as organizações passam por mudanças em sua orientação estratégica, tendendo a haver repercussões na estrutura. Na teoria institucional, que subsidia este trabalho, essas mudanças decorrem da busca de conformidade com padrões e regras de um dado campo, por meio do estabelecimento de estruturas e processos, como forma de se obter amparo e legitimidade (SCOTT, 1991). Esses ajustes ocorrem por meio de mecanismos de isomorfismo (DIMAGGIO; POWELL, 1983). Desse modo, gradativamente, ocorre a institucionalização, que, conforme Selznick (1971, p. 14), “[...] é algo que acontece a uma organização com o passar do tempo, refletindo sua história particular, o pessoal que nela trabalha, os grupos que engloba com os diversos interesses que criaram, a maneira como se adaptou ao seu ambiente". Conforme Tolbert e Zucker (1999), institucionalização refere-se ao processo que transforma crenças, valores e ações em regras de conduta social, compartilhadas por mecanismos de aceitação e reprodução.

A institucionalização de práticas contribui para a formação da identidade organizacional, por deixar transparecer seus valores, ações e padrões, construídos e comprovados pelos atores sociais, ao mesmo tempo em que são reconhecidos pela sociedade, favorecendo a legitimidade da organização. Desse modo, considerando a perspectiva da teoria institucional, busca-se responder à seguinte pergunta: quais os fatores determinantes na institucionalização da Responsabilidade Social Empresarial na Cagece?

Os objetivos específicos resumem-se em analisar os seguintes fatores determinantes desse processo de institucionalização, a saber: 1) inovações tecnológicas, aspectos legais e forças de mercado que conduzem à habitualização; 2) monitoramento interorganizacional e teorização que conduzem à objetificação; 3) impactos positivos, resistência e defesa de grupos de interesse que conduzem à sedimentação.

A pesquisa é de natureza quantitativa e descritiva, realizada mediante um survey, que teve como instrumento de coleta um questionário estruturado a partir dos temas valores, transparência e governança; público interno; e meio ambiente, dos Indicadores Ethos.

Além desta introdução, o artigo tem cinco seções. Nas seções dois e três discute-se o referencial teórico concernente à responsabilidade social empresarial e o referente à teoria institucional, respectivamente. A quarta seção subdivide-se em duas partes. Na primeira parte, apresenta-se a empresa foco do estudo e, em seguida, discute-se o tema do saneamento básico. $\mathrm{Na}$ segunda, aborda-se a metodologia. A quinta seção trata da apresentação e da análise dos dados, seguida, por fim, das conclusões. 


\section{A RESPONSABILIDADE SOCIAL EMPRESARIAL}

A responsabilidade social empresarial pode ser definida como um compromisso com a sociedade, expresso por meio de atos e atitudes que afetam positivamente, de modo amplo ou circunscrito, alguma comunidade (ASHLEY, 2002). Reconhecendo a pluralidade de visões acerca do tema, Abeysuriya, Mitchell e White (2007) argumentam que, no campo, há um comum propósito de facilitar a mudança em direção a um futuro social e ecologicamente sustentável, mediante ações empresarias voluntárias. Neste estudo, utiliza-se a definição do Instituto Ethos, segundo o qual a responsabilidade social empresarial é uma forma de gestão que

[...] se define pela relação ética e transparente da empresa com todos os públicos com os quais ela se relaciona e pelo estabelecimento de metas empresariais compatíveis com o desenvolvimento sustentável da sociedade, preservando recursos ambientais e culturais para as gerações futuras, respeitando a diversidade e promovendo a redução das desigualdades sociais (INSTITUTO ETHOS, 2009a).

Para o alcance proposto pela RSE, foram criadas diversas ferramentas, destacando-se: o Balanço Social, como demonstrativo das ações sociais da empresa; o Demonstrativo do Valor Adicionado (DVA), relatório que identifica quanto de valor a empresa agrega à sociedade e como esse valor é repartido entre os agentes; o Global Reporting Initiative (GRI), acordo internacional, que visa difundir as diretrizes para a organização de relatórios de sustentabilidade aplicáveis globalmente e as certificações como a Social Accountability (SA 8000); a Occupational Health and Safety (BS 8800) e a Accountability (AA1000), que, como ressalta Tenório (2006, p. 42), visam “[...] padronizar um conjunto mínimo de indicadores referentes aos aspectos éticos e de responsabilidade social na condução dos negócios".

Inerente ao conceito de RSE, está a preocupação com os impactos que uma organização exerce sobre o meio ambiente, a sociedade e as demais organizações, podendo gerar mudanças significativas para a qualidade de vida. Portanto, deve haver transparência com as partes envolvidas nesse processo de transformação do ambiente. Como afirma Machado Filho (2002, p. 91), “[...] a gestão com base na teoria dos stakeholders envolve a alocação de recursos organizacionais e a consideração dos impactos desta alocação em vários grupos de interesses dentro e fora da organização". Os Indicadores Ethos, definidos como uma ferramenta interna de aprendizado e autoavaliação da gestão no que se refere à incorporação de práticas de RSE ao planejamento estratégico (INSTITUTO ETHOS, 2009b), são amplamente utilizados na mensuração e no monitoramento do desempenho social,

O Instituto Ethos visa contribuir para que as empresas adotem práticas responsáveis, considerando todos os stakeholders, mediante o redirecionamento de orientações meramente econômicas, abrindo espaço para perspectivas mais amplas, inclusive no campo social. Contribui, assim, para a formação de empresas que possam ser reconhecidas como cidadãs. A esse respeito, Chaves e Ahsley (2005) argumentam que uma empresa cidadã, além de ganhar maior legitimidade perante a sociedade e o Estado, fortalecendo sua imagem, usufrui de outros benefícios, como ter, por exemplo: a) maior capacidade de atrair e reter talentos; b) maior comprometimento e lealdade dos empregados; c) maior aceitação por parte de clientes e consumidores; d) maior facilidade de acesso a financiamentos.

Os temas e subtemas dos indicadores Ethos, sumarizados no Quadro 1, constituem um guia potencialmente capaz de levar as empresas a um patamar de destaque no âmbito da responsabilidade social. Os indicadores são constituídos de sete grandes temas, subdivididos em um conjunto de ações. Sua missão é dupla - avaliar o estado das práticas e explorar a melhoria do desempenho.

\begin{tabular}{|c|c|}
\hline \multirow{3}{*}{$\begin{array}{c}\text { TEMAS } \\
\text { VALORES, TRANSPARENCIA E } \\
\text { GOVERNANÇA }\end{array}$} & SUBTEMAS \\
\hline & Autoregulação da conduta \\
\hline & Relações transparentes com a sociedade \\
\hline \multirow[b]{2}{*}{ PÚBLICO INTERNO } & $\begin{array}{l}\text { Dialogo e participacão } \\
\text { Respeito ao individuo }\end{array}$ \\
\hline & Trabalho decente \\
\hline \multirow{2}{*}{ MEIO AMBIENTE } & Responsabilidade com as gerações futuras \\
\hline & Gerenciamento do impacto ambiental \\
\hline FORNECEDORES & Seleção, avaliação e parceria com \\
\hline \multirow{2}{*}{$\begin{array}{c}\text { CONSUMIDORES E CLIENTES } \\
\text { COMUNIDADE }\end{array}$} & Dimensâo social do consumo \\
\hline & $\begin{array}{l}\text { Relações com a comunidade local } \\
\text { Acẫo social }\end{array}$ \\
\hline \multirow{2}{*}{ GOVERNO E SOCIEDADE } & Transparência política \\
\hline & Liderança social \\
\hline
\end{tabular}

Como argumentam Melo Neto e Froes (2004 p. 
Teresa Cristina Aguiar Lima, Augusto Cézar de Aquino Cabral, Maria Naiula Monteiro Pessoa, Sandra Maria dos Santos, Debora Cardoso do Nascimento

27), “[...] as ações de responsabilidade social exigem periodicidade, método e sistematização e, principalmente, gerenciamento efetivo por parte das empresas-cidadãs" Compreender sua institucionalização é fundamental.

\section{A TEORIA INSTITUCIONAL E O PROCESSO DE INSTITUCIONALIZAÇÃO DE TOLBERT E ZUCKER}

Conforme Machado-da-Silva e Gonçalves (1999), a teoria institucional resulta da convergência de corpos teóricos da ciência política, da sociologia e da economia, que incorporam em suas proposições a ideia de instituições e de padrões, de comportamento, de normas de valores, de crenças e de pressupostos, que envolvem indivíduos, grupos e organizações. De acordo com Hodgson (1998, p. 168), “[...] o institucionalismo refere-se às instituições, hábitos, regras e sua evolução. Porém, o institucionalismo não objetiva construir um modelo geral simplificado com base em suas ideias. Pelo contrário, tais ideias favorecem um forte ímpeto em direção a abordagens de análise específicas e historicamente localizadas" ()¿i. A teoria institucional busca entender por que as organizações adotam determinadas formas, buscando explicar homogeneidade ao invés de diferenciação (PUGH; HICKSON, 2004).

A abordagem institucional representa uma visão complementar na compreensão do processo de desenvolvimento econômico das nações ou, ainda, da evolução histórica das sociedades. Como arcabouço teórico-metodológico, conforme Tolbert e Zucker (1999), também há de se institucionalizar, pois há pouco consenso sobre a definição de conceitos chaves, mensurações ou métodos em seu âmbito. Essa abordagem tem duas versões: o velho institucionalismo, com destaque para o trabalho de Selznick (1971), e o novo institucionalismo, com ênfase para as obras de DiMaggio e Powell (1983) e North (1981).

Nas relações sociais, a abordagem institucional preocupa-se com o que há de enraizado na sociedade em termos de valores, ações e padrões que são estabelecidos e legitimados com base nas relações entre os atores sociais (QUINELLO, 2007). Assim, o institucionalismo pode ser caracterizado, conforme Huntington (1965, p. 12), “[...] como o processo pelo qual organizações e procedimentos adquirem valor e estabilidade".
Fonseca (2002) define institucionalização como o processo de transformar crenças e ações em regras de conduta social, que, ao longo do tempo, por influência de mecanismos de aceitação e reprodução, tornamse padrões e passam a ser encaradas como rotinas naturais, ou concepções compartilhadas da realidade. O processo de institucionalização se encontra, em todas as sociedades, mas, comporta vários graus nos diversos sistemas e subsistemas de uma sociedade (TATTO, 2005). A institucionalização gera padrões de comportamento, definidos como legítimos em uma dada situação.

Tolbert e Zucker (1999) afirmam que o processo de institucionalização constitui-se de processos seqüenciais em três estágios:

- Habitualização (estágio pré-institucional): envolve o desenvolvimento de comportamentos padronizados para a solução de problemas e a associação de tais comportamentos a estímulos particulares. Compreende inovações e mudanças efetuadas em resposta a problemas específicos que resultam em estruturas em estágio de pré-institucionalização, limitadas em termos de operação e, geralmente, pouco permanentes. Leva em consideração soluções adotadas em outras organizações, com possibilidade de ocorrência de mimetismo;

- Objetivação (estágio semi-institucional): implica o desenvolvimento de significados gerais compartilhados ligados aos comportamentos, para a transposição de ações de um contexto para outro. Consiste no desenvolvimento de consenso entre os decisores sobre o valor da estrutura, com base na obtenção e análise de informações sobre a sua disseminação em outras organizações (monitoramento interorganizacional), implicando na difusão da estrutura. Nesse estágio, os líderes, defensores das mudanças, desempenham papel central, realizando as tarefas de teorização que objetivam atribuir legitimidade cognitiva e normativa geral; e

- Sedimentação (estágio de total institucionalização): leva à institucionalização total, por meio da atuação de três variáveis: resistência de grupos, apoio continuado de grupos de defensores e correlação positiva com resultados esperados. Caracteriza-se não apenas pela propagação completa das estruturas por todo o grupo de atores teorizados como adotantes adequados, mas 
também pela perpetuação de estruturas por um longo período de tempo.

\section{ASPECTOS METODOLÓGICOS}

\subsection{A empresa do estudo e o saneamento urbano no Brasil}

As companhias de água e esgoto, como é o caso da empresa foco deste estudo, a Companhia de Água e Esgoto do Ceará (CAGECE), prestam serviços de natureza essencial, o do saneamento básico, setor que, como ressalta Cavinatto (2003), apesar dos significativos avanços, ainda carece de melhorias. A esse respeito, destaca-se a Lei Federal $n^{\circ} 11.445$, de 2007, que estabelece diretrizes para a regulação dos serviços de saneamento básico. A atuação ética e socialmente responsável é precondição essencial (CABRAL et al., 2011).

A escolha da CAGECE deve-se à sua posição de liderança dentre as companhias de água e esgoto do país e à relevância socioeconômica e estratégica do seu setor de atuação. Trata-se de uma sociedade de economia mista, da qual o Governo do Estado detém 84\% das ações, a Prefeitura Municipal de Fortaleza 15,6\% e outros acionistas 0,4\% (CAGECE, 2007). A Cagece é a quinta maior empresa do estado e a segunda em desempenho social. Em sua declaração de missão e em seus valores a empresa ressalta a sustentabilidade e a responsabilidade social e ambiental. A partir de 2005, seguindo tendências mercadológicas de empresas de diferentes segmentos, bem como de seu próprio campo organizacional, foi criada uma estrutura específica para tratar da responsabilidade social empresarial, caracterizando, assim, um processo de isomorfismo (CAGECE, 2009).

Em 1981, a CAGECE inaugurou o sistema PacotiRiachão-Gavião, com capacidade para armazenar 511 milhões de metros cúbicos de água. No mesmo ano, a rede coletora de esgoto chegava a $460 \mathrm{~km}$, atendendo a $18 \%$ da população. Em julho de 2001, a Cagece completou 30 anos com uma nova estrutura organizacional, formada por unidades de negócio e/ou de serviços, na capital e no interior do estado, tendo, desde, então, investido em planejamento estratégico, mediante macro projetos em várias áreas (CAGECE, 2010a). Para a CAGECE, a responsabilidade social integra sua missão, com atividades direcionadas tanto para o público interno quanto para o externo, tendo desenvolvido, recentemente seu Código de Ética e Conduta e seu Plano Diretor de Responsabilidade Social (CAGECE, 2010b).

$\mathrm{Na}$ análise da evolução do saneamento urbano em países industrializados, Abeysuriya, Mitchell e White (2006) identificam quatro fases. Na primeira, com o surgimento de cidades não planejadas em torno dos centros de manufatura, no início da revolução industrial, os arranjos sanitários não eram gerenciados, havendo, assim, altos níveis de poluição em áreas específicas e um péssimo nível de saúde pública. Conforme Goddard (1996), tais condições levaram à "revolução sanitária", no meio do século XIX. A segunda fase, a da infraestrutura centralizada, foi marcada pela construção em larga escala de um sistema de canalização para o suprimento de água tratada e, também, para o transporte de dejetos, tendo assim por foco tanto as questões de poluição urbana quanto as de saúde pública. $\mathrm{O}$ transporte de esgoto transferiu o ônus da questão ambiental para os pontos de descarte. A terceira fase, denominada neocentralizada, é focada na modificação do estágio centralizado para atender uma nova prioridade - a redução dos impactos ambientais negativos -, como o despejo de esgoto. Caracteriza-se, por exemplo, pela construção de interceptores oceânicos, para liberar o esgoto longe da costa. Avanços recentes nesse estágio têm como centro de interesse a busca de soluções visando superar o tratamento de "final de tubo" por enfoques modernos. A quarta fase, a emergente, centra-se na preocupação com a sustentabilidade, em um enfoque sistêmico, integrado e contingencial na busca de soluções gerenciais e tecnológicas.

Conforme Abeysuriya, Mitchell e White (2007), o estágio atual da infraestrutura sanitária nos países industrializados é uma combinação entre o estágio neocentralizado e o - ainda embrionário - quarto estágio. Por seu interesse fixo na sustentabilidade, é nesse estágio que se vislumbra maior alinhamento com o tema da responsabilidade social empresarial.

As empresas de saneamento têm como deveres relacionados à responsabilidade socioambiental a redução da desigualdade de acesso à água e aos serviços de saneamento, e a busca da inovação tecnológica para evitar a contaminação e o desperdício da água nos sistemas de distribuição (MOE; RHEINGANS, 2006). O governo é um dos parceiros essenciais dessas empresas 
Teresa Cristina Aguiar Lima, Augusto Cézar de Aquino Cabral, Maria Naiula Monteiro Pessoa, Sandra Maria dos Santos, Debora Cardoso do Nascimento

no cumprimento de seu papel social, contribuindo com políticas de financiamento e de infraestrutura que permitam a universalização do acesso aos serviços.

Em relação à atuação do governo federal brasileiro quanto aos investimentos em políticas públicas de saneamento, Santoni (2010) apontou o seguinte quadro: 1) predominância de uma arena de disputas políticas, sociais, econômicas e regionais; 2) falta de uma abordagem multidisciplinar, de forma a incluir na discussão a temática da sustentabilidade social, com princípios associados à justiça social; 3) prevalência, histórica, de um modelo de desenvolvimento urbano desigual; 4) desigualdade regional de acesso aos serviços de água e esgoto, com vantagem de disponibilidade para municípios da região sudeste.

O modelo de desenvolvimento econômico adotado pelo País destaca-se como um dos principais condicionantes da política pública de saneamento básico. Entre a década de 1970 e 1980, o modelo foi intervencionista e centralizador, tendo o governo investido prioritariamente numa infraestrutura básica voltada ao desenvolvimentismo de caráter industrial, configuração que prevalece ainda nos dias atuais (SANTONI, 2010). A maior parte do saneamento básico no Brasil, desde esse período, encontra-se nas mãos de grandes empresas estatais estaduais, algumas das quais com gestão não transparente.

Na década de 1990, houve uma reorientação política. Foram retomados princípios neoliberais os quais modificaram a natureza do saneamento brasileiro, que deixou de ter um caráter social para tornar-se um bem de consumo qualquer, passando a ser aberta a participação do setor privado no fornecimento do serviço. Crises econômicas geraram mudanças de regras quanto ao acesso aos recursos federais, restringindo os investimentos, o que provocou instabilidade regulatória, fragmentação institucional e fragilidade decisória, e desestimulou a melhoria do desempenho no setor de saneamento. Recentemente, por meio do Programa de Aceleração do Crescimento (PAC), do governo federal, houve uma ampliação dos investimentos, com uma distribuição mais igualitária das aplicações de recursos voltados para a melhoria das condições de vida de populações de baixa renda (SANTONI, 2010).

\subsection{Metodologia da pesquisa}

Este estudo pode ser caracterizado como de natureza quantitativa, dado que são utilizadas técnicas estatísticas na coleta e na análise dos dados. Trata-se de uma pesquisa bibliográfica, documental e de campo, realizada por meio de um survey. Quanto aos fins, classifica-se como investigação descritiva; assim, são estabelecidas relações entre as variáveis estudadas, de modo a se identificar os fatores e compreender sua interação em cada fase da institucionalização da responsabilidade social.

$\mathrm{O}$ estudo visa investigar o processo de institucionalização da responsabilidade social empresarial no contexto específico da Companhia e Água e Esgoto do Ceará (Cagece), à luz do modelo de Tolbert e Zucker (1999). A empresa foi escolhida em função de sua posição de liderança entre as companhias de saneamento básico do País e pela relevância socioeconômica e estratégica do seu setor de atuação.

Utilizou-se uma amostra não probabilística, tomando como base dois critérios para participação: ser empregado direto da empresa e estar lotado em Fortaleza, excluindo-se, assim, terceirizados e estagiários, ainda que atuantes na área de responsabilidade social. Considerouse o vínculo empregatício fundamental para possibilitar a compreensão do processo em estudo em uma perspectiva de longo prazo.

De um universo de 1.334 empregados diretos em todo o Estado do Ceará, 895 estão lotados em Fortaleza. O questionário foi enviado para toda a amostra selecionada. Do total de 895 empregados, 124 responderam a pesquisa.

Sobre o método de coleta utilizado, o survey, Malhotra (1999) afirma ser um dos métodos mais utilizados em pesquisas descritivas, ressaltando que consiste na aplicação de um questionário estruturado a uma amostra de uma população, destinado a provocar informações específicas dos respondentes. O método survey não se resume ao questionário propriamente, mas também à coleta, à comparação e à análise dos resultados.

O questionário de coleta de dados foi estruturado em dois blocos. O primeiro deles levanta dados acerca do perfil dos respondentes. O segundo, trata da institucionalização das práticas de RSE, subdividindo-se em duas partes.

$\mathrm{Na}$ primeira parte do segundo bloco, utiliza-se da escala de Likert, com cinco opções de resposta: (1) concordo muito; (2) concordo; (3) indeciso; (4) discordo; e (5) discordo muito. Apura-se, assim, a percepção dos 
respondentes acerca de um conjunto de práticas da empresa, descritas em forma de afirmativas construídas com base nos temas dos indicadores Ethos. A partir daí, faz-se o enquadramento das práticas de RSE em relação às fases do processo de institucionalização de Tolbert e Zucker (1999).

A segunda parte do segundo bloco é constituída de sete questões: a primeira questão trata da participação da empresa em ações de RSE; a segunda, aborda a intensidade ou o impacto das mudanças ocorridas na empresa com a adoção da RSE; a terceira, identifica, em uma escala de importância, de 1 (mais importante) a 6 (menos importante), os fatores que a empresa prioriza em relação às ações de RSE; a quarta, identifica os fatores que motivaram a empresa a adotar práticas de RSE; a quinta, investiga os fatores mais importantes na prática da RSE; a sexta, verifica a opinião dos respondentes quanto ao grau de relevância da institucionalização da RSE; a sétima e última questão visa identificar sugestões para o fortalecimento da área.

A análise e o tratamento dos dados foram realizados com o programa Statistical Package for the Social Sciences (SPSS) e com recursos do Excel, considerandose os diferentes tipos de questões que compõem o instrumento de coleta. O Quadro 2 evidencia o processo de análise dos dados, ponderando as categorias discutidas no referencial teórico e no questionário. Ressalta-se que o tema "fornecedores" não foi levado em conta para o âmbito da pesquisa, em função da inexistência de um mapeamento que contemplasse as questões relativas a toda a cadeia produtiva da Cagece e suas relações com fornecedores.

Quadro 2: Relação entre fases da institucionalização, os temas dos indicadores Ethos e os itens do questionário.

\begin{tabular}{|l|l|}
\multicolumn{1}{|c|}{$\begin{array}{c}\text { FASES DO PROCESSO DE } \\
\text { INSTITUCIONALIZACAO }\end{array}$} & ITENS DO QUESTIONÁRIO \\
\hline HABITUALIZAČAO & $\mathrm{c} ; \mathrm{d} ; \mathrm{g} ; \mathrm{m}$ \\
\hline OBJETIFICAÇÃO & $\mathrm{a} ; \mathrm{b} ; \mathrm{e} ; \mathrm{f} ; \mathrm{h} ; \mathrm{k} ; \mathrm{l} ;$ \\
\hline SEDIMENTAÇÃO & $\mathrm{i} ; \mathrm{j} ; \mathrm{n} ; \mathrm{o} ; \mathrm{p} ; \mathrm{q}$ \\
\hline \multicolumn{1}{|c|}{ TEMAS DOS INDICADORES ETHOS } & ITENS DO QUESTIONÁRIO \\
\hline VALORES, TRANSPARENCIA E GOVERNANÇA & $\mathrm{a} ; \mathrm{b} ; \mathrm{c} ; \mathrm{g} ; \mathrm{h} ; \mathrm{i}$ \\
\hline PÜBLICO INTERNO & $\mathrm{e} ; \mathrm{f}$ \\
\hline MEIO AMBIENTE & $\mathrm{i}$ \\
\hline CONSUMIDORES E CLIENTES & $\mathrm{m}$ \\
\hline COMUNIDADE & $\mathrm{o}$ \\
\hline GOVERNO E SOCIEDADE & $\mathrm{d} ; \mathrm{l}$ \\
\hline FORNECEDORES & não contemplado \\
\hline
\end{tabular}

Fonte: Elaborado pelos autores (2009).

Os dados foram analisados em termos do índice de concordância, que representa o percentual de respostas obtidas nas opções "concordo muito" e "concordo." Para um percentual igual ou superior a $50 \%$, considerou-se o índice de concordância favorável. Adicionalmente, para validar o grau de associação entre os itens do questionário e as fases de institucionalização, foram calculados os coeficientes de correlação de Pearson, considerando-se significativa a correlação quando o p-valor associado é menor do que 0,05 .

\section{O PROCESSO DE INSTITUCIONALIZAÇÃO DA RESPONSABILIDADE SOCIAL NA CAGECE}

Esta seção traz a apresentação e análise dos dados da pesquisa, ponderando os resultados do questionário e estabelecendo um confronto com o referencial teórico levantado. Está estruturada em quatro subseções, sendo a primeira subseção acerca do perfil dos respondentes. A segunda, trata do índice de concordância em relação às fases de institucionalização da RSE, conforme o modelo de Tolbert e Zucker(1998). A terceira, evidencia o índice de concordância em relação aos temas dos indicadores Ethos de RSE. A quarta e última seção aborda o grau de relevância atribuída à RSE.

\subsection{Perfil dos respondentes}

Este tópico se refere à apresentação dos respondentes, em relação ao cargo que ocupam, ao tempo de experiência na empresa e no cargo, ao sexo, à faixa etária, nível de escolaridade.

Dentre o grupo pesquisado, 39,4\% ocupam cargo de Analistas (profissionais de nível superior), outros 15,3\% são Assistentes (Ensino Médio) ou Técnicos (Técnico de Nível Médio), outros 11,2\% são Supervisores, seguidos de 7,2\% de Auxiliares. Dos 124 pesquisados, apenas $4 \%$ não especificaram o cargo que ocupam.

Apurou-se que o tempo médio de experiência na empresa é de 19,2 anos. Já o tempo de experiência no cargo é, em média, 10,3 anos. Logo, conclui-se que o grupo pesquisado é composto de profissionais que estão, em média, há 19 anos na Companhia, dos quais pelo menos 10 anos no cargo, estando, portanto, capazes de reconhecer determinados aspectos organizacionais.

No que respeita ao sexo, $58 \%$ dos pesquisados 
Teresa Cristina Aguiar Lima, Augusto Cézar de Aquino Cabral, Maria Naiula Monteiro Pessoa, Sandra Maria dos Santos, Debora Cardoso do Nascimento

pertencem ao sexo masculino e $42 \%$ ao feminino. Quanto à faixa etária, 54\% dos investigados estão acima de 45 anos, $15,3 \%$ na faixa entre 35 e 45 anos, e $29,8 \%$ no intervalo de 25 a 35 anos. Em relação à escolaridade, $37,1 \%$ possuem o nível superior completo, $30,6 \%$ têm pós-graduação, $23,4 \%$ possuem o ensino médio e apenas 8,9\% têm nível superior incompleto. O nível de instrução entre os sujeitos pesquisados é classificado como "bom", conforme disposto pela Cagece no relatório anual de incentivos para qualificação de seus colaboradores. No grupo dos que têm pós-graduação, a maioria dos colaboradores, 38, têm especialização; 7 têm mestrado; apenas 1 tem doutorado.

\section{Cargo Ocupado na Empresa}

\begin{tabular}{|l|c|c|}
\hline \multicolumn{1}{|c|}{ Cargos } & Qtde & \% \\
\hline Analista (de Gestão, Financeiro, Engenheiro, Químico, Logístico) & 49 & 39,5 \\
\hline $\begin{array}{l}\text { Assistente (Técnico, Administrativo, Comercial, de Arrecadação, } \\
\text { Operacional) }\end{array}$ & 19 & 15,3 \\
\hline Técnico (Administrativo, em Manutenção, em Química, Operacional) & 19 & 15,3 \\
\hline $\begin{array}{l}\text { Supervisor (Administrativo, de Desenvolvimento, de Planejamento, } \\
\text { Eletromecânico, Planejamento) }\end{array}$ & 14 & 11,3 \\
\hline Auxiliar (Administrativo, Operacional, Técnico) & 10 & 7,2 \\
\hline Diversos (Gerente, Motorista, Agente) & 8 & 6,4 \\
\hline Não respondeu & 5 & 4 \\
\hline \multicolumn{1}{|c|}{ TOTAL } & 124 & 100 \\
\hline Fonte: Dados da pesquisa. & &
\end{tabular}

\section{2 Índice de concordância em relação às fases de institucionalização da RSE, conforme o modelo de Tolbert e Zucker (1998)}

A primeira fase do processo, Habitualização, Tabela 1, envolve o desenvolvimento de comportamentos padronizados para a solução de problemas, o que, no caso da empresa, advém, em grande medida, da obediência às determinações da entidade reguladora, item "d", a Agência Reguladora de Serviços Públicos Delegados do Estado do Ceará (ARCE), que por sua vez segue diretrizes da Agência Reguladora de Águas e Saneamento (ARAS). Compreendem inovações e mudanças em resposta a problemas específicos, itens "g" e “m". Ademais, leva mem consideração soluções adotadas em outras empresas, com ocorrência de mimetismo, que se dá mediante alianças, como menciona o item "cc". Nessa fase, tem-se um índice de concordância favorável para fatores como atendimento à legislação, item "d", e às forças de mercado, itens "c $c$ " e "g", e investimento em tecnologia, item "m".
A segunda fase, a Objetificação, Tabela 2, caracterizase pela defesa das mudanças e das práticas por líderes que desempenham importante papel, realizando as tarefas de teorização que atribuem legitimidade cognitiva e normativa. Nessa fase, ocorre o desenvolvimento de consenso entre os decisores sobre o valor da estrutura, como sugerem os itens "a" e "k", com base na obtenção e análise de informações sobre a sua disseminação em outras organizações do mesmo campo, e no monitoramento interorganizacional, item " $\mathrm{h}$ ".

Nessa fase, verificam-se, também, índices favoráveis de concordância, com destaque para os itens "a", existência de setor/área que dá suporte à prática da RS..., e "l", viabilização de iniciativas de inclusão social..., acima de $80 \%$, Os itens "b" e "e" ficam em $60 \%$, enquanto os itens "f $\mathrm{f}$ " e " $\mathrm{k}$ " ficam em torno de $65 \%$. Apenas o item "h", referente a práticas de benchmarking e ao esforço de alinhar essas práticas aos objetivos estratégicos, obteve um índice inferior a $50 \%$.

A fase da Sedimentação, Tabela 3, leva à institucionalização total, por meio da atuação de três variáveis, conforme Tolbert e Zucker (1998): resistência de grupos de oposição, não constatada na empresa; apoio de grupos de defensores, itens "ij", “o" e "q"; e correlação positiva com resultados esperados, itens “ $\mathbf{j}$ ", “n” e “p”. Caracteriza-se pela propagação e perpetuação das estruturas. Quanto aos critérios de sedimentação, quatro apresentaram concordância favorável, acima de 50\%, com destaque para os itens "i", comprometimento com o desenvolvimento da sociedade, com $83,9 \%$, e "o", monitoramento do relacionamento com a comunidade, no âmbito social..., com $62,1 \%$. Apenas os itens " $j$ ”" e "p" obtiveram índices inferiores a 50\%, devendo-se, mais uma vez, destacar a peculiaridade deste último item, cujo enunciado confere conotação negativa à fase.

Tomando-se por base o coeficiente de correlação de Pearson, verifica-se que, em relação à primeira fase do processo de institucionalização, "Habitualização", todas as variáveis encontram-se correlacionadas, conforme demonstração na Tabela 4.

A propósito da segunda fase do processo de institucionalização, a Objetificação, da mesma forma que na 
primeira fase, todas as questões apresentam correlação entre si, de acordo com o evidenciado na Tabela 5.

No que concerne à fase da Sedimentação, a quantidade de informações não foi suficiente para evidenciar a correlação em quatro das seis questões, apresentada na Tabela 6.

\section{3 Índice de concordância em relação aos temas dos indicadores Ethos de RSE}

Em relação aos temas que tratam dos Valores, Transparência e Governança, o índice de concordância foi favorável, conforme é apontado na Tabela 7. Observase, pois, que a criação da área responsável pelo suporte à prática da RS e ao atendimento às orientações do órgão regulamentador da atividade apresenta-se com os maiores índices, $85,5 \%$ e 76,6\%, respectivamente. Os fatores relacionados à divulgação interna e ao contato com outras instituições que trabalham com RSE, apresentamse com valores limítrofes de 50\%.

O tema Público Interno apresenta índice de concordância favorável, demonstrado na Tabela 8 , logo a seguir. Sendo assim, pode-se garantir que as propostas desenvolvidas pela Cagece, no âmbito do diálogo e da participação, do respeito ao indivíduo, são reconhecidas como válidas pelos empregados.

O tema Meio Ambiente, que refere pontos como o gerenciamento do impacto ambiental, apresenta o segundo maior índice de concordância favorável $(83,9 \%)$, revelado na Tabela 9, logo a seguir, sendo, portanto, um forte tema respeitado pelo grupo pesquisado.

O tema Governo e Sociedade, que indica a necessidade de as empresas assumirem responsabilidade na formação de cidadãos, apresenta índices de concordância favoráveis de $76,6 \%$ e $81,5 \%$, de acordo com o grupo, como se vê na Tabela 10.

O tema Consumidores e Clientes, que indica o investimento necessário para a produção/oferta de produtos/serviços de qualidade e confiáveis, da mesma forma que os demais índices anteriores, apresenta índice de concordância favorável, conforme é evidenciado na Tabela 11 .

O tema Comunidade, que se dispõe a assegurar o respeito à cultura local, à educação e à propagação de valores sociais, segundo o grupo pesquisado, apresenta índice de concordância de $62,1 \%$, conforme o exposto na Tabela 12.

\subsection{Grau de relevância atribuída à $R S E$}

No processo de análise da relevância atribuída à RSE, verificou-se, inicialmente, a percepção dos respondentes quanto à participação da empresa no movimento de RSE ao longo dos últimos cinco anos, de acordo com o resultado denotado na Tabela 13. Para a grande maioria dos respondentes, 92,7\%, a participação da empresa na área de RSE foi crescente. Do total de respondentes, 49,2\% afirmam ter havido divulgação na empresa, inclusive em relação à estratégia corporativa, com a incorporação de novos processos de trabalho e a criação de órgãos na estrutura da empresa para lidar com essa questão; 29\% acreditam ter havido divulgação na empresa, porém sem proporcionar mudanças em seus processos e estrutura; e $14,5 \%$ consideram que a temática foi gradativamente discutida nas diversas esferas da empresa.

Nas Tabelas 14, 15 e 16, apresenta-se o grau de relevância atribuído às ações de RSE, sendo "N" a quantidade de entrevistados que responderam à pergunta que consta no item, e a "Média" o valor médio de pontuação obtida pelo item. Utilizou-se uma escala de pontuação de 1 a 6 , com 1 para o item mais importante e 6 para o menos importante. Portanto, uma média mais baixa significa que o item correspondente foi considerado mais importante.

Em relação às ações de RSE, o fator considerado mais importante foi o concernente aos compromissos éticos, à cultura organizacional e ao balanço social, com média de 2,38, seguido da educação e conscientização ambiental, com média de 2,42, e da dimensão social do serviço prestado, com 2,61. Verifica-se, assim, a alta relevância atribuída a questões relacionadas à autorregulação da conduta e a relações transparentes com a sociedade, que integram o tema Valores, Transparência e Governança dos indicadores Ethos. Também evidenciou-se relevante a preocupação com responsabilidade ante gerações futuras, que se insere no indicador Meio Ambiente. Ressalta-se, ainda, a importância atribuída à dimensão social do consumo, relacionada ao indicador Consumidores e Clientes (Tabela 14).

Os fatores considerados menos relevantes foram diálogo e participação, respeito ao indivíduo e trabalho decente, com média de 3,26; seleção criteriosa dos parceiros da organização, com média de 3,61; construção da cidadania por outras empresas, média de 3,99. Esses fatores relacionam-se, 
Teresa Cristina Aguiar Lima, Augusto Cézar de Aquino Cabral, Maria Naiula Monteiro Pessoa, Sandra Maria dos Santos, Debora Cardoso do Nascimento

respectivamente, com os temas Público Interno, Fornecedores e Governo e Sociedade, neste caso, mais especificamente, com o subtema Tranparência Política. (TABELA 14)

Quanto aos motivos que levaram a empresa a adotar as práticas de RSE, os fatores mais incentivadores, na visão do grupo pesquisado, foi o posicionamento da sociedade como um todo, com média de 2,0 , seguido da indicação dos clientes, com 2,33, e das ações governamentais, com 2,94. Três fatores obtiveram média superior a três, tendo, portanto, incentivado menos na adesão à RSE, sendo eles: o público interno, com média 3,4; a atuação dos sindicatos, com 3,93; a motivação de outras empresas, com média de 4,28.

No que diz respeito aos fatores importantes na prática da RSE, Tabela 16, destacaram-se, com as melhores médias (inferiores a três), eficiência na prestação de serviços, imagem ante o público externo e satisfação do público interno. Os demais fatores apresentaram médias superiores a três: transparência e prestação de contas para a sociedade, participação de pessoas de todos os níveis organizacionais na tomada de decisão e adoção de novas tecnologias e processos de trabalho. Desse modo, verifica-se que, na visão dos respondentes, o fator mais importante para a prática de RSE é a eficiência na prestação de serviços, contrapondo-se à adoção de novas tecnologias e processos de trabalho, fator tido como de menor relevância.

No tocante à institucionalização das práticas de RSE pela Cagece (Tabela 17), 53,3\% dos respondentes julgaram essa ação muito relevante, enquanto 40\% consideram relevante. Apenas 5\% julgaram ser irrelevante a institucionalização da RSE e aproximadamente $2 \%$ não responderam à pergunta. Verifica-se, assim, que aproximadamente $94 \%$ dos respondentes compreendem que a institucionalização da RSE confere legitimidade às ações desenvolvidas nesse campo.

Quanto à abrangência das mudanças provocadas pela adoção das práticas de RSE, 29,8\% dos respondentes caracterizam-nas como sendo de grande porte, e de impactos marcantes, tanto para o público interno quanto para o externo. Do total de respondentes, $50 \%$ consideraram tais mudanças de médio porte - $38.7 \%$ referem-se a impactos mais marcantes para o público externo e $11,3 \%$ a impactos mais marcantes para o público interno. Para $17 \%$, as mudanças foram de pequeno porte, sem significados concretos para o público externo e o interno.

Apresenta-se, por fim, as sugestões apontadas pelos respondentes para o fortalecimendo da área de RSE, com destaque para as seguintes ações: 1) proporcionar mais autonomia e poder de decisão aos responsáveis pela área de RSE; 2) disponibilizar mais claramente informações e materiais para a execução de tarefas; 3) integrar os princípios da RSE ao planejamento estratégico da empresa.

\section{CONCLUSÃO}

É crescente o envolvimento das empresas com o tema responsabilidade social empresarial. Contudo, em muitos casos, a formalização e a sistematização das práticas de RSE não ocorrem de forma continuada, o que inviabiliza o alinhamento dessas ações sociais à estratégia corporativa. Diante dessa constatação, este estudo dispôsse a investigar o processo de institucionalização da Responsabilidade Social, à luz do modelo proposto por Tolbert e Zucker (1998), tomando como lócus de pesquisa a Companhia de Água e Esgoto do Ceará (Cagece).

Quanto à habitualização, evidenciou-se, por exemplo, que a empresa investe em novas tecnologias com o propósito de melhorar a qualidade de seus serviços, item “m”, e segue as determinações da entidade reguladora de sua atuação, item “d”. Constatou-se, porém, que maior esforço deve ser realizado na promoção de palestras e encontros, envolvendo empregados, clientes, comunidade e governo para ampliar a difusão das práticas de RSE, item " $\mathrm{g}$ ".

$\mathrm{Na}$ análise da fase da habitualização, evidenciou-se, por exemplo, que a empresa investe em novas tecnologias com o propósito de melhorar a qualidade de seus serviços, item " $m$ ", e segue as determinações da entidade reguladora de sua atuação, item "d". Constatou-se, porém, que deve ser realizado maior esforço na promoção de palestras e encontros, envolvendo empregados, clientes, comunidade e governo, com o fim de ampliar a difusão das práticas de RSE, item "g".

Pelos dados analisados na objetificação, verificouse que, em relação ao monitoramento, a empresa realiza estudos sobre RS tanto interna quanto externamente, por diversos meios, item "b". Também busca, em outras instituições, propostas na área de RS e desenvolve 
estudos para aplicá-las, aliando-as aos próprios objetivos estratégicos, item "e". Na prática da teorização por parte dos "champions", líderes que propagam a relevância da RSE, há um forte consenso pela adoção de uma postura transparente e ética no desenvolvimento de iniciativas de inclusão social, item "l”. Em alinhamento aos esforços de monitoração e teorização, confirma-se um consenso social entre os decisores acerca do valor de uma estrutura própria, responsável pela RSE, item " $k$ ". Ressalta-se, porém, que o moderado índice de concordância expresso no item " $h$ ", relativo às ações de benchmarking realizadas pela empresa junto a outras organizações, parece indicar que deve haver maiores esforços de alinhamento dessas ações aos objetivos estratégicos próprios.

No que concerne à sedimentação, viu-se, por exemplo, que a empresa entende que a disseminação e a adoção da RSE trazem legitimidade às suas ações, item " $q$ ”. Como evidência, detecta-se um alto índice de concordância pelo comprometimento da empresa com o desenvolvimento da sociedade, por meio de programas como de educação sanitária, coleta seletiva de lixo, entre outros, item “i”. Observa-se, ainda, que a empresa monitora seu relacionamento com a comunidade, reavaliando suas ações, item "o".

Conclui-se que o processo de institucionalização como um todo ainda está em andamento, com progressos moderados, mas com mudanças a serem formalizadas, sistematizadas, consolidadas e disseminadas, de modo que se possa, eventualmente, constatar o reflexo da continuidade histórica das práticas de responsabilidade social na estrutura, como sinal de sua institucionalização como propõem Tolbert e Zucker.

\section{REFERÊNCIAS}

ABEYSURIYA, Kumudini; MITCHELL, Cynthia; WHITE, Stuart. Can corporate social responsibility resolve the sanitation question in developing Asian countries? Ecological Economics, 62, p. $174-183,2007$.

ASHLEY, P. Ética e responsabilidade social nos negócios. São Paulo: Saraiva, 2002

CABRAL, Augusto C.; GEMAQUE, Lúcio; SANTOS, Sandra; PESSOA, M. Naiula. Estágio de evolução da responsabilidade social em companhias de água e esgoto: um estudo sob a perspectiva dos gestores da área de RSE. In: CONGRESSO USP DE CONTROLADORIAE CONTABILIDADE-CONGRESSO USP DE CONTROLADORIA E CONTABILIDADE, 11, 2011, São Paulo-SP. Anais... São Paulo: USP, 2011.
CARROLL, Archie B. A three-dimensional conceptual model of corporate social performance. Academy of Management Review, v. 4, n. 4, p. 497-505,1979

CAVINATTO, Vilma M. Saneamento básico: fonte de saúde e bem-estar. 2. ed. São Paulo: Moderna, 2003.

CHAVES, J.; ASHLEY, P. Racionalidades para a ética empresarial e a gestão da empresa cidadã. In: P. Ashley (coord), Ética e responsabilidade social nos negócios. 2 . ed. Rio de Janeiro: Saraiva, 2005.

CAGECE. Relatório Anual 2007. Disponível em: <http://www. cagece.com.br/institucional/relatorio-anual $>$. Acesso em 25 de outubro de 2009.

Demonstrações financeiras 2008. Disponível em: $<$ http://www.cagece.com.br/institucional/relatorio-anual/ institucional/demonstracoes-financeiras $>$. Acesso em 25 de outubro de 2009.

. Institucional. Disponível em: $<$ http://www.ceara.

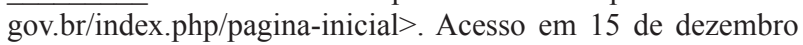
de 2010a.

. Planejamento estratégico. Disponível em: <http:// www.cagece.com.br/institucional/historia/planejamentoestrategico $>$. Acesso em 15 de dezembro de 2010b.

DIMAGGIO, P.; POWELL, W. The iron cage revisited: institutional isomorphism and collective rationality in organizational fields. American Sociological Review, v. 48, p. 147-160, 1983

FACHIN, R.; MEDONÇA, J. Selznick: uma visão da vida e da obra do precursor da perspectiva institucional na teoria organizacional. In: CARVALHO, C.; VIEIRA, M. (Eds), Organizações, instituições e poder no Brasil. Rio de Janeiro: FGV, p. 29-46, 2003.

FONSECA, M. F. Certificação de sistemas de produção e processamento de produtos orgânicos de origem animal: história e perspectiva. Cadernos de Ciência e Tecnologia, v. 19, n. 2, p. 267-97, 2002.

GODDARD, N. "A mine of wealth"? The Victorians and the agricultural value of sewage. Journal of Historical Geography, v. 22, n. 3, p. 274-290, 1996.

GONÇALVES FILHO, Cid; BRITO, Hélvio; GOSLING, Marlusa; SOUKI, Gustavo Q. Os impactos da responsabilidade social corporativa na reputação da empresa e nas intenções comportamentais das comunidades: estudo empírico. ContextusRevista Contemporânea de Economia e Gestão, Fortaleza, v. 7, n. 1, p. 37-54, jan/jun 2009.

HODGSON, G. The approach of institutional economics. Journal of Economic Literature, v. 36, p. 166-192, 1998. 
Teresa Cristina Aguiar Lima, Augusto Cézar de Aquino Cabral, Maria Naiula Monteiro Pessoa, Sandra Maria dos Santos, Debora Cardoso do Nascimento

HUNTINGTON, S. Political development and political decay. World Politics, v. 17, n. 3, p. 386-430, 1965.

INSTITUTO ETHOS. Perguntas freqüentes. Disponível em: $<\mathrm{http}$ //www.ethos.org.br/DesktopDefault.aspx?TabID=3344\& Alias $=$ Ethos $\&$ Lang $>$. Acesso em 20 novembro de $2009^{\mathrm{a}}$.

Indicadores Ethos. Disponível em: <http://www. ethos.org.br/_Uniethos/documents/IndicadoresEthos_2009_ port.pdf $>$. Acesso em 20 novembro de 2009b.

MACHADO-DA-SILVA, C.; GONÇALVES, S. Nota técnica: a teoria institucional. In: CLEGG, S.; HARDY, C.; NORD, W. (Orgs.) Handbook de estudos organizacionais: modelos e novas questões em estudos organizacionais, São Paulo: Atlas, v.1, p $.220-226$.

MACHADO FILHO; C. A. P. Responsabilidade social corporativa e a criação de valor para as organizações: um estudo multicasos. 204 f. Tese de Doutorado. Faculdade de Economia, Administração e Contabilidade, Universidade de São Paulo, 2002.

MALHOTRA, N. Pesquisa de marketing: orientação aplicada. Porto Alegre: Bookman, 1999.

MELO NETO, F. P.; FROES, C. Responsabilidade social e cidadania empresarial: a administração do terceiro setor. Rio de Janeiro: Qualitymark, 1999.

MOE, Christine L.; RHEINGANS, Richard D. Global challenges in water, sanitation and health. Journal of Water and Health, v. 4, sup.1, p. 41-57, 2006.

NORTH, Douglass C. Structure and change in economic history. New York: W. W. Norton \& Co, 1981.

OLIVEIRA, Bruno C.; OLIVEIRA, J. D'Arc; OLIVEIRA, L. G. L.; OLIVEIRA, M. C.; ANDRADE, M. C.; MARQUES, M. V. Responsabilidade social corporativa: um estudo de caso de empresas exportadoras cearenses do setor calçadista. ContextusRevista Contemporânea de Economia e Gestão, Fortaleza, v. 4, n. 1, p. 17-28, jan/jun 2006.

PUGH, D.; HICKSON D. Os teóricos das organizações. Rio de Janeiro: Qualitymark, 2004.

QUINELLO, Robson. A teoria institucional aplicada à administração: entenda como o mundo invisível impacta na gestão dos negócios. São Paulo: Novatec, 2007.

RUBIN, H.; RUBIN I. Qualitative interviewing: the art of hearing data. London: Sage Publications, 1995.

SANTONI, Lauseani. Saneamento básico e desigualdades: o financiamento federal da política pública (2003-2009). Dissertação (Mestrado em Desenvolvimento Sustentável). 160f. Universidade de Brasília, Brasília, 2010.

SELZNICK, Philipe. Liderança em administração. Rio de Janeiro: FGV, 1971.
SCOTT, W. Unpacking institutional arguments. In: POWELL, W.; DIMAGGIO, P. (Eds). The new institutionalism in organizational analysis. Chicago: The University of Chicago Press, p. 164-182, 1991.

TATTO, Luiz. Institucionalização, estrutura e comportamento das universidades públicas estaduais paranaenses. $280 \mathrm{f}$. Tese (Doutorado em Engenharia de Produção). Programa de PósGraduação em Engenharia de Produção,Florianópolis: UFSC, 2005.

TENÓRIO, Fernando G. (Org.) Responsabilidade social empresarial: teoria e prática. Rio de Janeiro: FGV, 2006.

TOLBERT, P.; ZUCKER, L. A institucionalização da teoria institucional. In: CLEGG, S.; C. HARDY, C.; NORD, W. (Orgs.). Handbook de estudos organizacionais: modelos e novas questões em estudos organizacionais. v. 1. São Paulo: Atlas, p. 196-219,1999. 


\section{APÊNDICE A}

Tabela 1 - Critérios de habitualização avaliados

\begin{tabular}{|l|c|}
\hline \multicolumn{1}{|c|}{ HABITUALIZAÇÃo } & $\begin{array}{c}\text { ÍNDICE DE } \\
\text { CONCORDÂNCIA } \\
\text { (\%) }\end{array}$ \\
\hline $\begin{array}{l}\text { c) A empresa desenvolve parcerias com entidades que trabalham com o conceito de RS, como Federação } \\
\text { das Indústrias do Estado do Ceará - FIEC, universidades e centros de pesquisa, por exemplo o Instituto } \\
\text { Ethos de Empresa e Responsabilidade Social. }\end{array}$ & 55,6 \\
\hline d) A empresa segue às determinações da entidade reguladora de sua atuação, no caso ... & 76,6 \\
\hline $\begin{array}{l}\text { g) A empresa promove palestras, encontros, pesquisas na área de RSE envolvendo empregados, } \\
\text { fornecedores, clientes, comunidade, Governo. }\end{array}$ & 50,0 \\
\hline m) A empresa investe em novas tecnologias com o propósito de melhorar a qualidade de seus serviços. & 66,1 \\
\hline
\end{tabular}

Fonte: Dados da pesquisa de campo (2009).

Tabela 2 - Critérios da objetificação avaliados

\begin{tabular}{|l|c|}
\hline \multicolumn{1}{|c|}{ OBJETIFICAÇÃo } & $\begin{array}{c}\text { ÍNDICE DE } \\
\text { CONCORDÂNCIA } \\
\text { (\%) }\end{array}$ \\
\hline a) A empresa possui área/setor responsável que dá suporte à prática da RSE. & 85,5 \\
\hline $\begin{array}{l}\text { b) A empresa realiza estudos sobre RS, tanto interna quanto externamente, por meio de programas de } \\
\text { sugestões, canal de consultas via e-mail, canal de atendimento. }\end{array}$ & 59,7 \\
\hline $\begin{array}{l}\text { e) A empresa oferece ao empregado propostas contínuas de melhoria em relação a fatores como: } \\
\text { qualidade de vida e segurança no trabalho, plano de desenvolvimento profissional, incentivo à } \\
\text { escolaridade. }\end{array}$ & 59,7 \\
\hline $\begin{array}{l}\text { f) A empresa oferece ações voltadas para o público interno que respeitam à diversidade, sem distinção de } \\
\text { sexo, cor, religião ou classe social. }\end{array}$ & 63,7 \\
\hline $\begin{array}{l}\text { h) A empresa busca, em outras instituições, propostas na área de RS e desenvolve estudos para aplicá-las, } \\
\text { aliando-as aos próprios objetivos estratégicos. }\end{array}$ & 48,4 \\
\hline $\begin{array}{l}\text { k) A empresa acredita que a criação de uma estrutura própria, responsável pelas atribuições da RS, } \\
\text { favorece a implementação de práticas socialmente responsáveis. }\end{array}$ & 66,1 \\
\hline $\begin{array}{l}\text { l) A empresa viabiliza iniciativas de inclusão social (programas de estágios, "Projeto Treine”, por } \\
\text { exemplo), de incentivo à cultura (Coral das Águas, Teatro), de apoio projetos sociais, de forma } \\
\text { transparente e ética. }\end{array}$ & 81,5 \\
\hline
\end{tabular}

Fonte: Dados da pesquisa de campo (2009).

Tabela 3 - Critérios da sedimentação avaliados

\section{SEDIMENTAÇÃO}

i) A empresa é comprometida com o desenvolvimento da sociedade, através de programas como de educação sanitária, coleta seletiva de lixo, entre outros.

j) A empresa nos encontros, palestras realizadas dentro do tema Responsabilidade Social, permite a apresentação de novas propostas na área, inclusive avaliando as propostas já existentes.

n) A empresa demonstra claramente os resultados alcançados pela RS.

o) A empresa acompanha seu relacionamento com a comunidade, no âmbito social, reavaliando ações de trabalho.

p) A empresa acredita que a atuação de uma instituição que visa lucro é incompatível com a prática de RS.

ÍNDICE DE CONCORDÂNCIA

q) A empresa entende que a disseminação e adoção da RS traz legitimidade (reconhecimento) às suas ações.

Fonte: Dados da pesquisa (2009). 
Teresa Cristina Aguiar Lima, Augusto Cézar de Aquino Cabral, Maria Naiula Monteiro Pessoa, Sandra Maria dos Santos, Debora Cardoso do Nascimento

Tabela 4 - Correlação para a fase da Habitualização

\begin{tabular}{|c|c|c|c|c|c|c|}
\hline \multicolumn{2}{|r|}{ HABITIUALIZAÇÃO } & a) & c) & d) & g) & $\mathrm{m})$ \\
\hline \multirow{2}{*}{ a) } & Correlação de Pearson & &, $386(* *)$ & $.224(*)$ & $.325(* *)$ & $324(* *)$ \\
\hline & p-valor & & 0,000 & 0,013 & 0,000 & 0,000 \\
\hline \multirow[t]{2}{*}{ c) } & Correlação de Pearson & $.386(* *)$ & & $.443(* *)$ & $.481(* *)$ & $.239(* *)$ \\
\hline & p-valor & 0,000 & & 0,000 & 0,000 & 0,000 \\
\hline \multirow{2}{*}{ d) } & Correlação de Pearson & $224(*)$ &, $443(* *)$ & & $.275(* *)$ & ,463(**) \\
\hline & p-valor & 0,013 & 0,000 & & 0.002 & 0,000 \\
\hline \multirow[b]{2}{*}{ g) } & Correlação de Pearson & $325(* *)$ &, $481(* *)$ &, $275(* *)$ & & $295(* *)$ \\
\hline & $\mathrm{p}$-valor & 0.000 & 0,000 & 0.002 & & 0.001 \\
\hline \multirow{2}{*}{ m) } & Correlação de Pearson & $324(* *)$ &, $239(* *)$ & $463(* *)$ & $.295(* *)$ & \\
\hline & p-valor & 0,000 & 0,000 & 0,000 & 0,001 & \\
\hline
\end{tabular}

*Correlação significante a 0,05

**Correlação significante a 0,01

Fonte: Dados da pesquisa (2009).

Tabela 5 - Correlação para a fase da Objetificação

\begin{tabular}{|c|c|c|c|c|c|c|c|}
\hline \multicolumn{2}{|r|}{ OBJETIFICAÇÃO } & b) & e) & f) & h) & k) & 1) \\
\hline \multirow[t]{2}{*}{ b) } & Correlação de Pearson & &, $426(* *)$ &, $364(* *)$ &, $436(* *)$ &, $215(*)$ &, $256(* *)$ \\
\hline & p-valor & & 0,000 & 0,000 & 0,000 & 0,017 & 0,004 \\
\hline \multirow[t]{2}{*}{ e) } & Correlação de Pearson &, $426(* *)$ & &, $532(* *)$ &, $430(* *)$ & ,291(**) &, $458(* *)$ \\
\hline & p-valor & 0,000 & & 0,000 & 0,000 & 0,001 & 0,000 \\
\hline \multirow[t]{2}{*}{ f) } & Correlação de Pearson &, $364(* *)$ &, $532(* *)$ & &, $436(* *)$ &, $326(* *)$ &, $578(* *)$ \\
\hline & p-valor & 0,000 & 0 & & 0,000 & 0,000 & 0,000 \\
\hline \multirow[t]{2}{*}{ h) } & Correlação de Pearson &, $436(* *)$ &, $430(* *)$ &, $436(* *)$ & &, $465(* *)$ &, $322(* *)$ \\
\hline & p-valor & 0,000 & 0,000 & 0,000 & & 0,000 & 0,000 \\
\hline \multirow[t]{2}{*}{ k) } & Correlação de Pearson &, $215(*)$ &, $291(* *)$ &, $326(* *)$ &, $465(* *)$ & &, $341(* *)$ \\
\hline & p-valor & 0,017 & 0,001 & 0,000 & 0,000 & & 0,000 \\
\hline \multirow[t]{2}{*}{ 1) } & Correlação de Pearson &, $256(* *)$ &, $458(* *)$ &, $578(* *)$ &, $322(* *)$ &, $341(* *)$ & \\
\hline & p-valor & 0,004 & 0,000 & 0,000 & 0,000 & 0,000 & \\
\hline
\end{tabular}

*Correlação significante a 0,05

**Correlação significante a 0,01

Fonte: Dados da pesquisa (2009).

Tabela 6 - Correlação para a fase da Sedimentação

\begin{tabular}{|c|c|c|c|c|c|c|c|}
\hline \multicolumn{2}{|r|}{ SEDIMENTAÇÃO } & i) & j) & n) & o) & p) & q) \\
\hline \multirow{2}{*}{ i) } & Correlação de Pearson & &, $478(* *)$ &, $386(* *)$ &, $402(* *)$ & 0,015 &, $428(* *)$ \\
\hline & p-valor & & 0,000 & 0,000 & 0,000 & 0,867 & 0,000 \\
\hline \multirow{2}{*}{ j) } & Correlação de Pearson &, $478(* *)$ & &, $443(* *)$ &, $461(* *)$ &, $185(*)$ & ,376(**) \\
\hline & p-valor & 0,000 & & 0,000 & 0,000 & 0,042 & 0,000 \\
\hline \multirow{2}{*}{ n) } & Correlação de Pearson &, $386(* *)$ &, $443(* *)$ & &, $481(* *)$ &, $239(* *)$ &, $271(* *)$ \\
\hline & p-valor & 0,000 & 0,000 & & 0,000 & 0,008 & 0,002 \\
\hline \multirow{2}{*}{ o) } & Correlação de Pearson &, $402(* *)$ &, $461(* *)$ &, $481(* *)$ & &, $324(* *)$ &, $388(* *)$ \\
\hline & p-valor & 0,000 & 0,000 & 0,000 & & 0,000 & 0,000 \\
\hline \multirow{2}{*}{ p) } & Correlação de Pearson & 0,015 &, $185(*)$ &, $239(* *)$ &, $324(* *)$ & & 0,055 \\
\hline & p-valor & 0,867 & 0,042 & 0,008 & 0,000 & & 0,546 \\
\hline \multirow{2}{*}{ q) } & Correlação de Pearson &, $428(* *)$ &, $376(* *)$ &, $271(* *)$ &, $388(* *)$ & 0,055 & \\
\hline & p-valor & 0,000 & 0,000 & 0,002 & 0,000 & 0,546 & \\
\hline
\end{tabular}

*Correlação significante a 0,05

**Correlação significante a 0,01

Fonte: Dados da pesquisa (2009). 
Tabela 7: Índice de concordância com Tema Valores, Transparência e Governança

\begin{tabular}{|l|c|}
\hline \multicolumn{1}{|c|}{ VALORES, TRANSPARÊNCIA E GOVERNANÇA } & $\begin{array}{c}\text { INDICE DE } \\
\text { CONCORDÂNCIA } \\
\text { (\%) }\end{array}$ \\
\hline a) A empresa possui área/setor responsável que dá suporte à prática da RSE. & 85,5 \\
\hline $\begin{array}{l}\text { b) A empresa realiza estudos sobre RSE, tanto interna quanto externamente, através de programas de } \\
\text { sugestões, canal de consultas via e-mail, canal de atendimento. }\end{array}$ & 59,7 \\
\hline $\begin{array}{l}\text { c) A empresa desenvolve parcerias com entidades que trabalham com o conceito de RS, como Federação } \\
\text { das Indústrias do Estado do Ceará - FIEC, universidades e centros de pesquisa, por exemplo o Instituto } \\
\text { Ethos de Empresa e Responsabilidade Social. }\end{array}$ & 55,6 \\
\hline $\begin{array}{l}\text { g) A empresa promove palestras, encontros, pesquisas na área de RSE envolvendo empregados, } \\
\text { fornecedores, clientes, comunidade, Governo. }\end{array}$ & 50,0 \\
\hline $\begin{array}{l}\text { h) A empresa busca, em outras instituições, propostas na área de RSE e desenvolve estudos para aplicá-las, } \\
\text { aliando-as aos próprios objetivos estratégicos. }\end{array}$ & 48,4 \\
\hline $\begin{array}{l}\text { j) A empresa nos encontros, palestras realizadas sobre o tema RSE, permite a apresentação de novas } \\
\text { propostas na área, inclusive avaliando as propostas já existentes. }\end{array}$ & 48,4 \\
\hline
\end{tabular}

Fonte: Dados da pesquisa (2009).

Tabela 8: Índice de concordância com Tema Público Interno

\begin{tabular}{|l|c|}
\hline \multicolumn{1}{|c|}{ PÚBLICO INTERNO } & \multicolumn{1}{|c|}{$\begin{array}{c}\text { ÍNDICE DE } \\
\text { CONCORDÂNCIA (\%) }\end{array}$} \\
\hline $\begin{array}{l}\text { e) A empresa oferece ao empregado propostas contínuas de melhoria em relação a fatores como: } \\
\text { qualidade de vida e segurança no trabalho, plano de desenvolvimento profissional, incentivo à } \\
\text { escolaridade. }\end{array}$ & 59,7 \\
\hline $\begin{array}{l}\text { f) A empresa oferece ações voltadas para o público interno que respeitam a diversidade, sem } \\
\text { distinção de sexo, cor, religião ou classe social. }\end{array}$ & 63,7 \\
\hline
\end{tabular}

Fonte: Dados da pesquisa (2009).

Tabela 9: Índice de concordância com Tema Meio Ambiente

\begin{tabular}{|l|c|}
\hline \multicolumn{1}{|c|}{ MEIO AMBIENTE } & $\begin{array}{c}\text { ÍNDICE DE } \\
\text { CONCORDÂNCIA } \\
\text { (\%) }\end{array}$ \\
\hline $\begin{array}{l}\text { i) A empresa é comprometida com o desenvolvimento da sociedade, através de programas como de } \\
\text { educação sanitária, coleta seletiva de lixo, entre outros. }\end{array}$ & 83,9 \\
\hline
\end{tabular}

Fonte: Dados da pesquisa (2009).

Tabela 10: Índice de concordância com Tema Governo e Sociedade

\begin{tabular}{|l|c|}
\hline \multicolumn{1}{|c|}{ GOVERNO E SOCIEDADE } & $\begin{array}{c}\text { INDICE DE } \\
\text { CONCORDÂNCIA } \\
\text { (\%) }\end{array}$ \\
\hline $\begin{array}{l}\text { d) A empresa segue as determinações da entidade reguladora de sua atuação, no caso, a Agência } \\
\text { Reguladora de Serviços Públicos Delegados do Estado do Ceará - ARCE. }\end{array}$ & 76,6 \\
\hline $\begin{array}{l}\text { 1) A empresa viabiliza iniciativas de inclusão social (programas de estágios, "Projeto Treine", por exemplo), } \\
\text { de incentivo à cultura (Coral das Águas, Teatro), de apoio projetos sociais, de forma transparente e ética. }\end{array}$ & 81,5 \\
\hline
\end{tabular}

Fonte: Dados da pesquisa (2009).

Tabela 11: Índice de concordância com Tema Consumidores e Clientes

\begin{tabular}{|c|c|}
\hline CONSUMIDORES E CLIENTES & $\begin{array}{c}\text { INDICE DE } \\
\text { CONCORDÂNCIA } \\
(\%)\end{array}$ \\
\hline m) A empresa investe em novas tecnologias com o propósito de melhorar a qualidade de seus serviços. & 66,1 \\
\hline
\end{tabular}

Fonte: Dados da pesquisa (2009).

Tabela 12: Índice de concordância com Tema Comunidade

\begin{tabular}{|l|c|}
\hline \multicolumn{1}{|c|}{ COMUNIDADE } & $\begin{array}{c}\text { ÍNDICE DE } \\
\text { CONCORDÂNCIA } \\
\text { (\%) }\end{array}$ \\
\hline $\begin{array}{l}\text { o) A empresa acompanha seu relacionamento com a comunidade, no âmbito social, reavaliando ações de } \\
\text { trabalho. }\end{array}$ & 62,1 \\
\hline
\end{tabular}

Fonte: Dados da pesquisa (2009). 
Teresa Cristina Aguiar Lima, Augusto Cézar de Aquino Cabral, Maria Naiula Monteiro Pessoa, Sandra Maria dos Santos, Debora Cardoso do Nascimento

Tabela 14: Ações mais importantes em relação à RSE, conforme os temas Ethos

\begin{tabular}{|c|c|c|}
\hline A empresa considera ... & $\mathbf{N}$ & Média \\
\hline ... compromissos éticos, cultura organizacional, balanço social & 106 & 2,38 \\
\hline ... educação e conscientização ambiental & 106 & 2,42 \\
\hline ... dimensão social do serviço prestado & 97 & 2,61 \\
\hline ... diálogo e participação, respeito ao indivíduo, trabalho decente & 103 & 3,26 \\
\hline ... seleção criteriosa dos parceiros da organização & 98 & 3,61 \\
\hline ... construção da cidadania por outras empresas & 96 & 3,99 \\
\hline
\end{tabular}

Fonte: Dados da pesquisa (2009).

Tabela 15: Motivação da empresa para adotar as práticas da RSE

\begin{tabular}{|l|c|c|}
\hline \multicolumn{1}{|c|}{ Item } & N & Média \\
\hline Sociedade como um todo & 93 & 2,00 \\
\hline Clientes & 86 & 2,33 \\
\hline Governo & 85 & 2,94 \\
\hline Público interno (funcionários) & 85 & 3,40 \\
\hline Sindicatos & 84 & 3,93 \\
\hline Outras empresas & 78 & 4,28 \\
\hline Não sei responder & 20 & 1,35 \\
\hline
\end{tabular}

Fonte: Dados da pesquisa (2009).

Tabela 16: Fatores importantes para a prática de RSE

\begin{tabular}{|l|c|c|}
\hline \multicolumn{1}{|c|}{ Item } & N & Média \\
\hline Eficiência na prestação de serviços & 108 & 2,43 \\
\hline Imagem ante o público externo, com melhorias concretas de serviços & 109 & 2,70 \\
\hline Satisfação do público interno (funcionários) & 100 & 2,88 \\
\hline Transparência e prestação de contas para a sociedade como um todo & 100 & 3,01 \\
\hline A participação de pessoas de todos os níveis da organização na tomada de decisão & 101 & 3,34 \\
\hline Adoção de novas tecnologias e processos de trabalho & 100 & 3,73 \\
\hline
\end{tabular}

Fonte: Dados da pesquisa (2009).

Tabela 17 - Classificação da relevância da institucionalização das práticas de RSE

\begin{tabular}{|l|c|c|}
\hline \multicolumn{1}{|c|}{ Relevância } & Qtde & \% \\
\hline Muito relevante & 66 & 53,3 \\
\hline Relevante & 50 & 40,3 \\
\hline Irrelevante & 6 & 4,8 \\
\hline Não respondeu & 2 & 1,6 \\
\hline Total & 124 & 100 \\
\hline
\end{tabular}

Fonte: Dados da pesquisa (2009). 